\title{
Morphological Changes of Mammalian Nucleoli during Spermatogenesis and Their Possible Role in the Chromatoid Body Assembling
}

\author{
Rita Luiza Peruquetti, Sebastião Roberto Taboga, \\ and Maria Tercília Vilela de Azeredo-Oliveira \\ Department of Biology, Sao Paulo State University, UNESP/IBILCE, Rua Cristovao Colombo, 2265, \\ 15054-000 Sao Jose do Rio Preto, SP, Brazil \\ Department of Biology, Sao Paulo State University, UNESP/IBILCE, Rua Cristovao Colombo, 2265, 15054-000 Sao Jose do Rio Preto, \\ SP, Brazil \\ Correspondence should be addressed to Rita Luiza Peruquetti, ritaperuquetti@yahoo.com.br
}

Received 5 November 2011; Accepted 8 December 2011

Academic Editors: A. Hergovich, P. Lavia, and M. Yamaguchi

Copyright ( $) 2012$ Rita Luiza Peruquetti et al. This is an open access article distributed under the Creative Commons Attribution License, which permits unrestricted use, distribution, and reproduction in any medium, provided the original work is properly cited.

\begin{abstract}
Chromatoid body (CB) is a typical cytoplasmic organelle of germ cells, and it seems to be involved in RNA/protein accumulation for later germ-cell differentiation. Despite most of the events in mammals spermatogenesis had been widely described in the past decades and the increase in the studies related to the $\mathrm{CB}$ molecular composition and physiology, the origins and functions of this important structure of male germ cells are still unclear. The aims of this study were to describe the nucleolar cycle and also to find some relationship between the nucleolar organization and the $\mathrm{CB}$ assembling during the spermatogenesis in mammals. Cytochemical and cytogenetics analysis showed nucleolar fragmentation in post-pachytene spermatocytes and nucleolar reorganization in post-meiotic spermatids. Significant difference in the number and in the size of nucleoli between spermatogonia and round spermatids, as well as differences in the nucleolar position within the nucleus were also observed. Ultrastructural analysis showed the $\mathrm{CB}$ assembling in the cytoplasm of primary spermatocytes and the nucleolar fragmentation occurring at the same time. In conclusion our results suggest that the CB may play important roles during the spermatogenesis process in mammals and that its origin may be related to the nucleolar cycle during the meiotic cell cycle.
\end{abstract}

\section{Introduction}

Spermatogenesis is the biological process of gradual transformation of germ cells into spermatozoon over an extended period of time within the boundaries of the seminiferous tubules of the testis. This process involves cellular proliferation by repeated mitotic divisions, duplication of chromosomes, genetic recombination through crossover, reduction division by meiotic cell division to produce haploid spermatids, and terminal differentiation of the spermatids into spermatozoon [1]. This important biological process has been extensively studied and described, and currently there are appropriate biological terminologies to describe every step of the spermatozoon formation [2]. However, there are some recent important aspects of the spermatogenesis, as, for example, the assembling and the function of the chromatoid body (CB), which is not so clearly understood. The CB is a typical cytoplasmic organelle of haploid germ cells and is involved in RNA and protein accumulation for later germcell differentiation [3, 4]. Many studies have been carried out intending to clarify the origins and functions of this intriguing cytoplasmic structure of male germ cells. Recent efforts to elucidate the functions of the $\mathrm{CB}$ have been detecting the presence of the Mouse Vasa Homologue protein $(\mathrm{MVH})$, which is an ATP-dependent DEAD-box RNA helicase playing a role in the establishment and differentiation of germ cells, closely associated with CB in several organisms [5-8]. Another interesting molecular component of CBs 
is the MAEL protein, an ortholog of Drosophila's highmobility group box protein Maelstrom that is associated not only with the silenced XY body but also with unsynapsed autosomes interacting directly with the chromatin remodeler SNF5/INI1 and chromatin-associated protein SIN3B. The presence of MAEL in this critical compartment of male germ cells and its interactions provide a link suggesting the involvement of the miRNA pathway in meiotic silencing of unsynapsed chromatin (MSUC) [9]. Despite many efforts to elucidate the $\mathrm{CB}$ functions, its main function is still unclear. $\mathrm{CB}$ origin is also still uncertain although many theories trying to elucidate it exist. Some authors suggest that the origin of the CB is nuclear $[10,11]$. Others have proposed that the $\mathrm{CB}$ precursor is a dense interstitial material occurring between mitochondrial clusters [12], or that it is a result of the mitochondrial products that are released in the cell cytoplasm [13]. However, still others have suggested that the $\mathrm{CB}$ originates from nuages, a ribonucleoproteic complex derived from the nucleolus, which migrates to the cytoplasm during earlier spermatogenesis [14-18].

The nucleolus is a distinct nuclear territory involved in the compartmentalization of nuclear functions [19]. Therefore, ribosome biogenesis is the main function attributed to the nucleolus [20-22], and many studies have shown that nucleolus also has nonribosomal functions, including nucleotide modifications of several small RNAs, biosynthesis of the signal recognition particle and phased sequestration, and the release of proteins involved in gene silencing, senescence, and cell division [23]. Moreover, some proteins that are involved in the control of the cell cycle, such as Net1, Cdc14, and Sir2, are located in the nucleolar compartments [24-27], along with the tumor suppressor proteins ARF [28], p53, and Myc [29]. The nucleolus of germ cells seem to be involved in meiotic cell-cycle control, because most of the Pch2 protein, which is required for the meiotic checkpoint that prevents chromosome segregation when recombination and chromosome synapses are defective, localizes to the nucleolus [30].

Since both nucleolar and CB physiology are very important to the spermatogenesis process, the aims of the present study were to describe the nucleolar cycle and also to find some relationship between nucleolar organization and CBassembling process during the spermatogenesis in mammals. This study was performed by using cytochemical, cytogenetics, and ultrastructural analysis to follow the nucleolar cycle and the $\mathrm{CB}$ assembling in the seminiferous epithelium of Oryctolagus cuniculus (Mammalia, Lagomorpha).

\section{Material and Methods}

Investigations were carried out on 5 adult male Oryctolagus cuniculus (Mammalia, Lagomorpha). The animals were obtained from Sao Jose do Rio Preto School of Medicine Vivarium (FAMERP, Sao Jose do Rio Preto, SP, Brazil). All animals were housed under standard conventional conditions $\left(25^{\circ} \mathrm{C}, 40-70 \%\right.$ relative humidity, $12 \mathrm{~h}$ light $/ 12 \mathrm{~h}$ dark $)$ and allowed access to chow and water ad libitum. The animals were anaesthetized and killed by carbon dioxide gas inhalation, and after their deaths the animals were dissected, and their gonads were removed and prepared for each biological analysis.

2.1. Cytochemical Analysis. Testes of each animal were removed and immersed in a Karnovsky fixative solution for 36 hours. The material was embedded in glycol-methacrylate historesin. Sections (1-3 $\mu \mathrm{m}$ thick) were obtained in Leica RM 2155 microtome. Tissue sections were submitted to various cytological and cytochemical procedures, including hematoxylin-eosin (HE) [31], toluidine blue (TB), modified Critical Electrolyte Concentration for detecting RNA (CEC) [32], silver-ion impregnation (AgNOR) [33], and Feulgen reaction [34]. The sections of germ epithelium were evaluated under an Olympus BX 60 photomicroscope and documented using Image Pro-Plus; Media Cybernetics computer software, version 6.1 for Windows for image analysis.

In addition to the qualitative analysis of the nucleolar material distribution, the tissue sections that were subjected to silver ion impregnation were used for quantitative analysis, in order to determine the number of nucleoli in the spermatogonia and round spermatids, and also to measure the nuclear and nucleolar areas in the same types of cells.

\subsubsection{Determination of the Number of Nucleoli in the Sper- matogonia and Round Spermatids. The number of nucleoli was determined in all spermatogonia and round spermatids recorded in this study. Spermatogonia $(144.2 \pm 9.47)$ and round spermatids $(169.2 \pm 13.81)$ were considered from each specimen studied $(n=5)$. Due to the different amount of cells analyzed in each cell type, the percentage of the number of nucleolus in each cell type was calculated.}

2.1.2. Measuring the Nuclear and Nucleolar Areas of the Spermatogonia and Round Spermatids. Spermatogonia and round spermatids were photodocumented using an Olympus BX 40 photomicroscope and Image Pro-Plus Media Cybernetics computer software, version 4.5 for Windows. Next, both nuclear and nucleolar areas of these cells were measured using Image J-Image Processing and Analysis in Java software, Version 1.40 (http://rsb.info.nih.gov/ij/) for image analysis. The cells that had one single nucleolus were measured immediately, while the total area of those with two or more nucleoli was calculated by adding up the areas of each individual nucleolus.

2.2. Data Analysis. Normal distribution of the dataset was tested using Skewness and Kurtosis analysis [35], and variance homogenity was tested using the $F$ max test [36]. The number of nucleoli was compared between spermatogonia and round spermatids, and also within the same cell type using the Two-Factor Analysis of Variance, which was complemented using the LSD multiple comparisons test [36]. Nuclear and nucleolar areas of spermatogonia were compared to nuclear and nucleolar areas of round spermatids using an independent $t$ test [36]. Statistical significance was considered when $P>0.05$. 


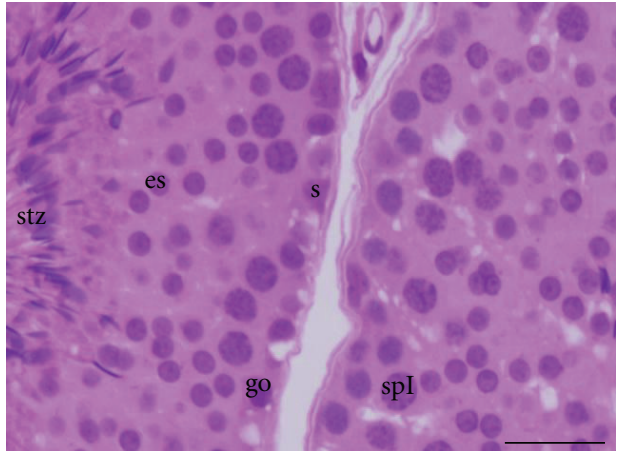

(a)

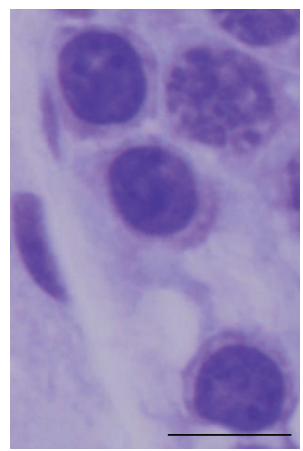

(c)

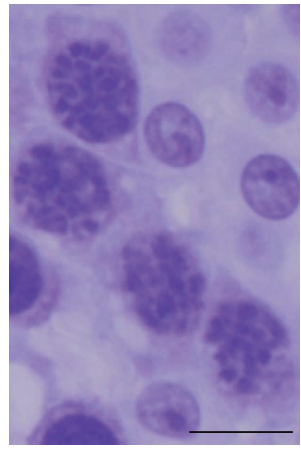

(d)

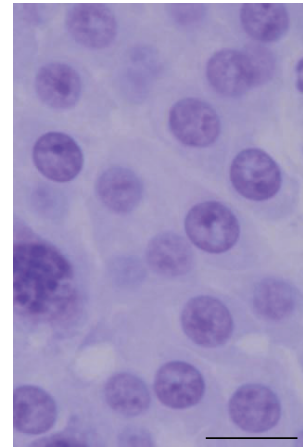

(e)

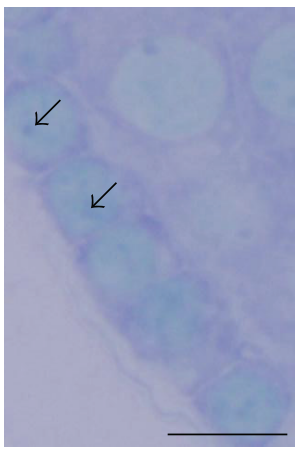

(f)

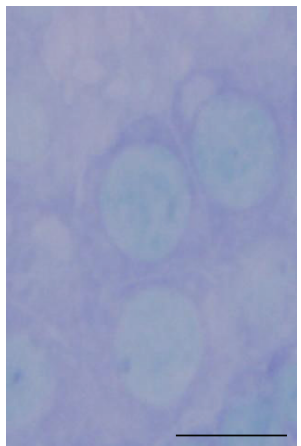

(g)

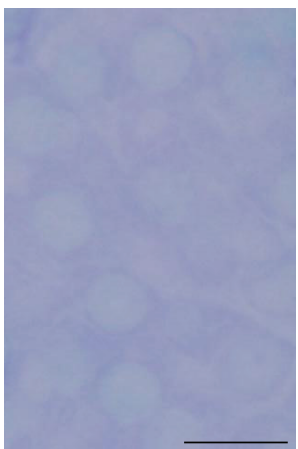

(h)

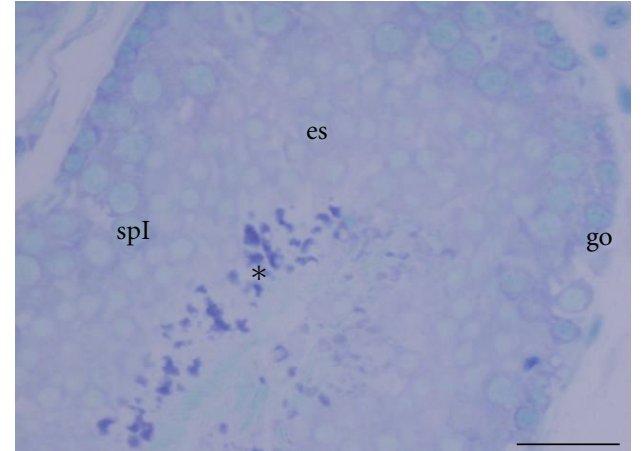

(b)

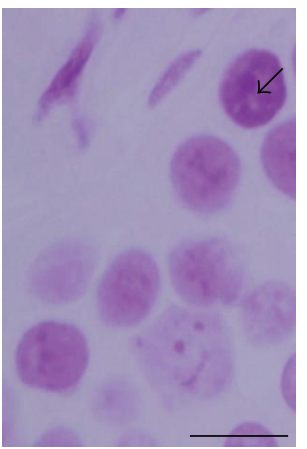

(i)

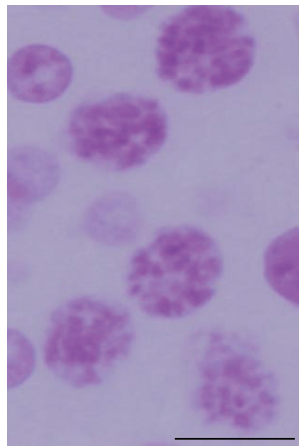

(j)

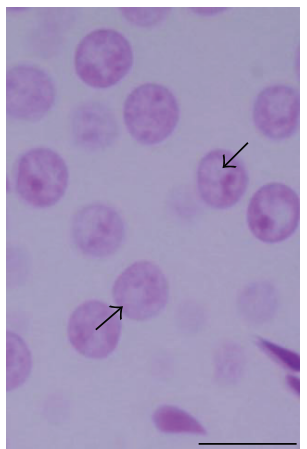

(k)

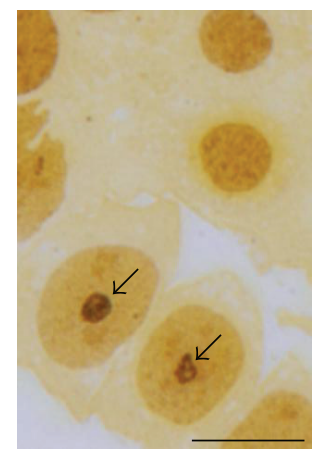

(l)

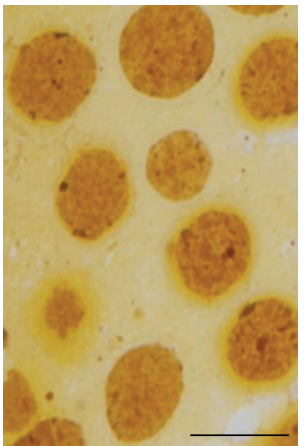

(m)

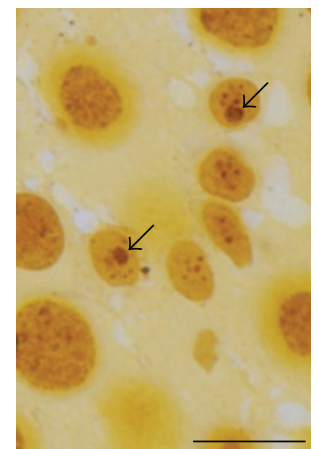

(n)

Figure 1: Cytological and cytochemical analysis of the germ epithelium of Oryctolagus cuniculus. (a) Hematoxylin-eosin (HE); (c-e) toluidine blue (TB); (b, f-h) modified critical electrolyte concentration method (CEC); (i-k) Feulgen reaction; (l-n) silver ion impregnation. ( $a$ and $b$ ) General view of the seminiferous tubules, where we can observe the distribution of the somatic and germ cells through the seminiferous epithelium: s (Sertoli cell); go (spermatogonia); spI (primary spermatocyte); es (round spermatids); stz (elongated spermatids); * (residual bodies). (c, f, i, and l) spermatogonia with fully organized nucleoli. (d, g, j, and m) spermatocytes I exhibiting fragmented nucleolar material disperse through the nuclei. ( $\mathrm{e}, \mathrm{h}, \mathrm{k}$, and $\mathrm{n}$ Reassembly of the nucleolar structure could be observed in the nuclei of round spermatids. Reorganized nucleoli were not observed using the CEC method (h). (f, k, l, and n) arrows (nucleolar corpuscles). Bars: (a and b) $50 \mu \mathrm{m}$; (c-n) $20 \mu \mathrm{m}$. 
2.3. Cytogenetic Analysis. Standard meiotic cells were obtained using the method introduced by [37] and adapted by [38]. Soon after, the testes were sectioned into small fragments and submitted to hypotonic treatment with $0.075 \mathrm{M}$ $\mathrm{KCl}$ for $20-30 \mathrm{~min}$. The material was then treated with a fresh fixative solution (methanol:glacial acetic acid, $3: 1$ ) for $30 \mathrm{~min}$, and this procedure was performed a minimum of two times per fragment. After fixation, some fragments were placed in the well of a depression slide with some drops of a $50 \%$ glacial acetic acid solution and mixed until a homogeneous cell suspension was obtained. One drop of this suspension was then deposited onto a clean slide, and heated to about $38^{\circ} \mathrm{C}$ with the aid of a fine-tipped Pasteur pipette. The drop was then sucked back into the pipette, forming a cell ring measuring about $1 \mathrm{~cm}$ in diameter on the slide, with the cells preferentially deposited on the border of the ring. These last two steps were repeated on 2-3 additional fields of the same slide. Then, the slides were submitted to silver ion impregnation (AgNOR) [33] to follow the nucleolar material distribution during the meiotic division in the germ cells. The preparations were evaluated under an Olympus BX 60 photomicroscope and documented using Image ProPlus; Media Cybernetics, version 6.1 for Windows computer software for image analysis.

2.4. Ultrastructural Analysis. Testes fragments of each animal were removed and sliced into small pieces, and samples of the germ epithelium were cut and immersed in a $3 \%$ glutaraldehyde plus $0.25 \%$ tannic acid solution in Millonig's buffer ( $\mathrm{pH} 7.3$ ) containing $0.54 \%$ glucose for 24 hours at room temperature [39]. After being washed with the same buffer, samples were postfixed in $1 \%$ osmium tetroxide for 1 hour at $4^{\circ} \mathrm{C}$, washed in Millonig's buffer, dehydrated in a graded acetone series, and embedded in Araldite resin. Ultrathin silver sections $(50-75 \mathrm{~nm})$ were cut using a diamond knife and stained with $2 \%$ alcoholic uranyl acetate for $30 \mathrm{~min}$ [40], followed by $2 \%$ lead citrate in sodium hydroxide for $10 \mathrm{~min}$ [41]. Samples were evaluated using a Leo-Zeiss 906 (Cambridge, UK) transmission electron microscope and documented using ITEM (Soft Image System-Veleta $2 \mathrm{~K} \times$ 2K TEM CCD Camera) software for image analysis.

2.5. Ethics Note. This study was approved by the Ethical Committee for Animal Research (CEEA) of Sao Paulo State University (UNESP) in Botucatu, Sao Paulo, Brazil, under protocol number $057 / 06$.

\section{Results}

3.1. Cytochemical Analysis. Hematoxylin-eosin (HE) cytological analysis was used to confirm the spermatogenesis pattern in the seminiferous tubules (Figure 1(a)). Stadia of development and type of cells present in the germ epithelium were ranked according to Leblond and Clermont [42]. Toluidine blue (TB) reaction revealed the cells of the male germ epithelium with an intense metachromasy in all of the nuclear domains (euchromatin, heterochromatin, nucleolus, and chromosomes) (Figures 1(c), 1(d), and 1(e)). The degree of metachromasy varied according to the compaction of genetic material, the ploidy of the cell nucleus, and the complexity of the nucleic acids with ribonucleoproteic (RNP) corpuscles. The TB reaction was performed as a control for the critical electrocyte concentration (CEC) variant method for RNA detection. CEC revealed spermatogonia with metachromatic nucleoli (Figure 1(f)), primary spermatocytes with fragmented nucleoli and nucleolar fragments surrounding the chromosomes (Figure $1(\mathrm{~g})$ ), and round spermatids with no organized nucleoli (Figure $1(\mathrm{~h})$ ). Several residual bodies were detected in the seminiferous epithelium lumen (Figure $1(\mathrm{~b})$ ). Feulgen reaction is a DNA-specific method in which all germ cell nuclei are dyed purple and are categorized according to their degree of ploidy, functional stage, and compaction of chromatin. Heterochromatic regions were more intensively dyed, and nucleoli were seen as light spots connected to these heterochromatic regions. In the spermatogonia (Figure 1(i)), the nucleolar area was larger than in both primary spermatocytes (Figure $1(\mathrm{j})$ ) and round spermatids (Figure $1(\mathrm{k})$ ), indicating the occurrence of fragmentation and reduction of the nucleolar area in the latter's cell type. Impregnation using silver ion (AgNOR) revealed the nucleolar regions in different germ cells. Spermatogonia were found to possess organized nucleoli (Figure 1(1)), primary spermatocytes possessed fragmented nucleoli (Figure $1(\mathrm{~m})$ ), and round spermatids possessed reorganized nucleoli (Figure $1(n)$ ) although they were found to be smaller than the spermatogonium nucleoli.

3.1.1. Determination of the Number of Nucleolus in the Spermatogonia and Round Spermatids. There was a correlation between the cell type and the number of nucleoli $(F=$ 3.63; $P>0.05)$. This correlation showed that the number of spermatogonia with one nucleolus was lower than the number of round spermatids with the same number of nucleolus. However, spermatogonia possessed 2, 3, or 4 nucleolus as frequently as round spermatids (Figure 2(a)).

3.1.2. Sizes of the Nuclear and Nucleolar Areas of the Spermatogonia and Round Spermatids. There were significant differences between the nuclear areas of spermatogonia and round spermatids $(t=9.64 ; P>0.05)$, and also between the nucleolar area of spermatogonia and round spermatids $(t=$ $10.14 ; P>0.05)$. In both results, the areas of spermatogonia were larger than the areas of round spermatids (Figure 2(b)).

3.2. Cytogenetic Analysis. Spermatogonia going through mitotic metaphase were not observed in the cytogenetic preparations, but the chromosomic number of the species was established as $2 n=44$ according to Korstanjea et al. [43]. Standard meiotic preparations impregnated using the silver ion method showed spermatogonia with large central nucleoli (Figure 3(a)). In primary spermatocytes in the zygotene stage (Figure 3(b)), fragmented nucleoli and nucleolar fragments distributed in the periphery of the nucleus and also surrounding the chromosomes were observed. Primary spermatocytes in pachytene stage (Figure 3(c)) possessed nucleolar fragments distributed mainly in the 


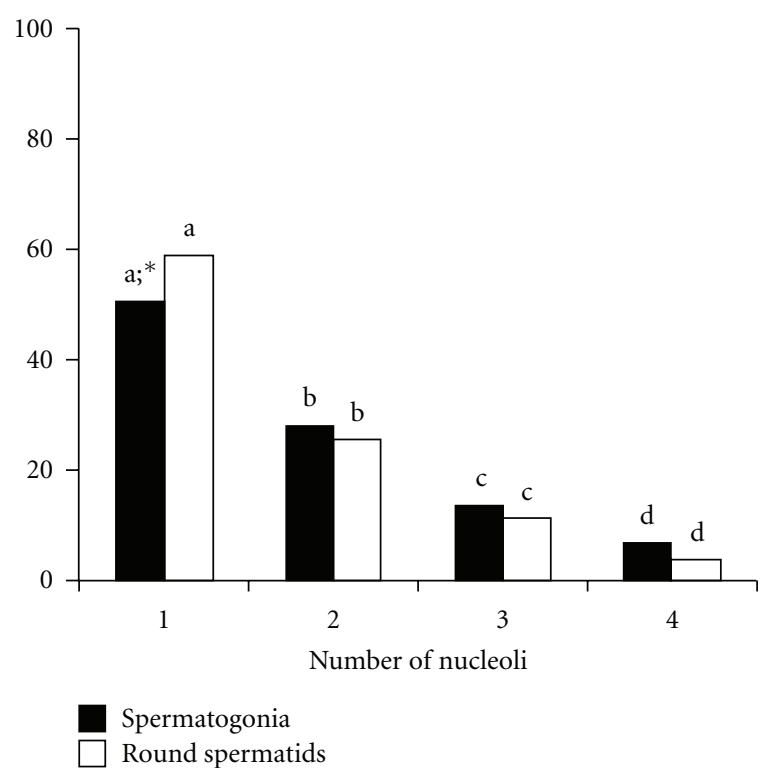

(a)
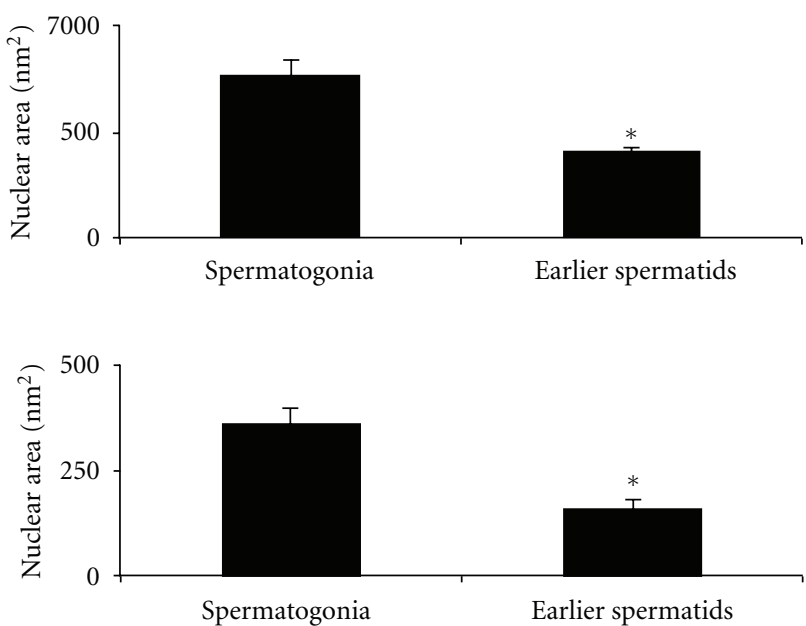

(b)

Figure 2: (a) Percentage of germ cells (spermatogonia and round spermatids) of Oryctolagus cuniculus that possessed 1 to 4 nucleoli. The letters represent a statistically difference in the number of nucleoli in each cell type, and the asterisk represents statistically difference between both cell types (LSD, $P<0.05)$. The means $( \pm$ SD) of the number of spermatogonia and round spermatids possessing 1,2 , 3, or 4 nucleoli were, spermatogonia: 1 nucleolus 61.33 ( \pm 13.72); 2 nucleoli 34.5 ( \pm 3.67$) ; 3$ nucleoli 17 ( \pm 3.42$)$; 4 nucleoli 9.33 ( \pm 6.06$)$. Round spermatids: 1 nucleolus $83.16( \pm 14.51) ; 2$ nucleoli $36.5( \pm 11.32)$; 3 nucleoli $16.66( \pm 3.97)$; 4 nucleoli $6.33( \pm 2.94)$. B: areas $\left(\mathrm{nm}^{2}\right)$ of the nuclei and nucleoli of spermatogonia and round spermatids. The asterisk $(*)$ represents a statistically significant difference between the cell types (independent $t$ test, $P<0.05$ ).

periphery of the nucleus. In advanced meiotic stages, such as metaphase I (Figure 3(d)), no nucleolar corpuscles were observed; however, strong spots of silver impregnation were observed in some chromosomes probably in the place where nucleolar organizer regions (NORs) are located. Round and elongated spermatids were observed possessing 1 to 4 nucleolar corpuscles (Figures 3(e) and 3(f)) preferentially located in the periphery of the nucleus. Spermatozoon possessed a strong silver ion impregnation in their middle piece and tail region (Figure $3(\mathrm{~g})$ ).

3.3. Ultrastructural Analysis. Spermatogonia did possess reticulated nucleoli organized in the nucleus center, but neither ribonucleoprotein nuages nor initial chromatoid bodies (CB) assembling was observed (Figures 4(a) and 4(b)). Complete nucleolar disorganization and cytoplasmic accumulation of ribonucleoprotein were observed in the primary spermatocytes in pachytene stages. Ribonucleoprotein accumulation in the cytoplasm of primary spermatocytes was observed both unassociated with other structures (Figure 4(b)) or in association with mitochondrial aggregates (Figures 4(c) and 4(d)). Nucleoli fully organized were observed again in the nucleus of round spermatids (Figures $4(\mathrm{e})$ and 5(a)), and CBs were observed in association with mitochondrial aggregates in the anterior nuclear region, where acrosome formation takes place (Figures 4(e), 4(f), $5(\mathrm{a})$, and $5(\mathrm{~b}))$. Elongated spermatids were shown also possessing organized nucleoli, and the migration of the complex composed by $\mathrm{CB}$ and mitochondrial aggregations to the posterior nucleus region, where the mitochondrial sheath and spermatozoon tail formation take place, was also observed (Figures 5(c), 5(d), and 5(e)). No dense ri-bonucleoprotein corpuscles were observed in the residual bodies after the formation of the mature spermatozoon (Figure 5(f)).

\section{Discussion}

Most recent studies focused on the molecular composition and function of the chromatoid body (CB), a structure present in the cytoplasm of male germ cells, suggest that this structure acts as a subcellular coordinator of different RNA-processing pathways and centralizes posttranscriptional mRNA control in the cytoplasm of haploid male germ cells $[7,44,45]$. The CB seems to be very important in the spermatogenesis process since mutations in some proteins located in this structure, such as tudor proteins (TDR1/MTR-1) and rat histocompatibility antigen (OX3) cause sterility in rats $[46,47]$. Besides of the importance of this structure, its origins are not fully understudied, and many different theories were thought aiming to understand where the $\mathrm{CB}$ molecular components come from nucleus $[10,11]$, mitochondria $[12,13]$, and/or nucleolus [14-18]. The nucleolus is a nuclear domain whose main function is linked to the ribosome synthesis [19]. However, many studies have shown that the nucleolus also has nonribosomal functions, including mitosis regulation, cell-cycle progression, cell proliferation, cell stress, biogenesis of ribonucleoprotein 


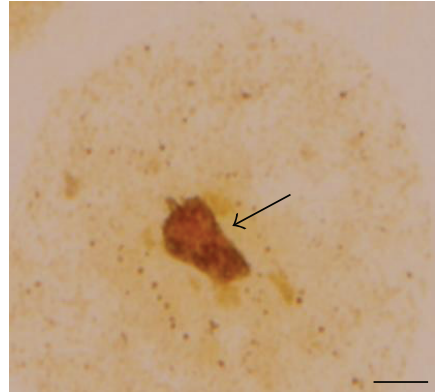

(a)

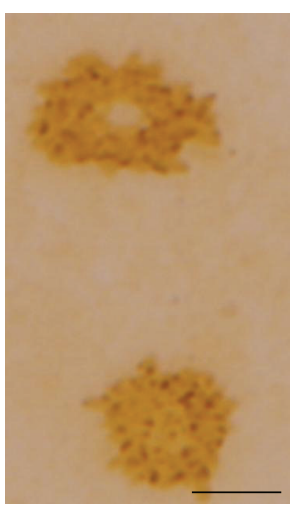

(d)

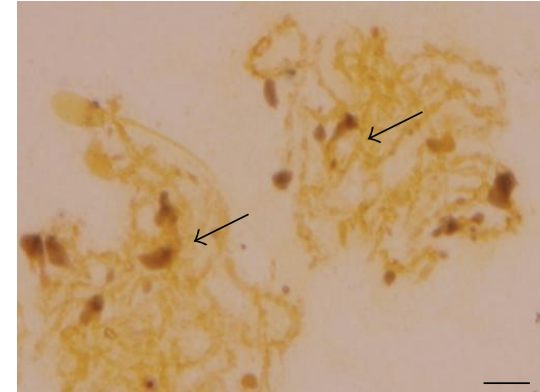

(b)

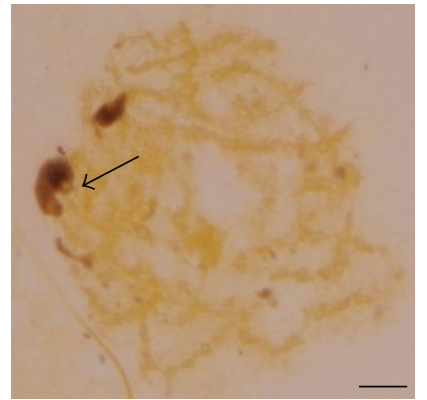

(c)

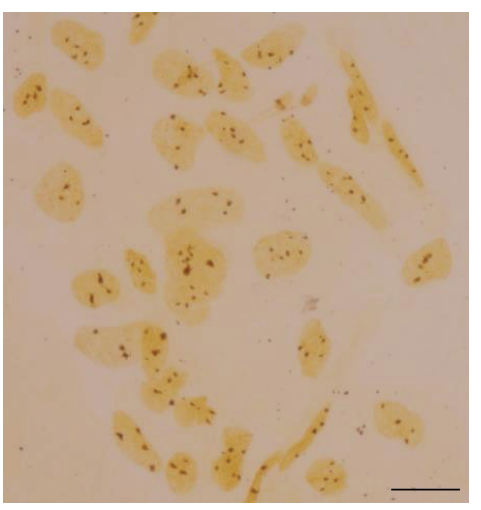

(e)

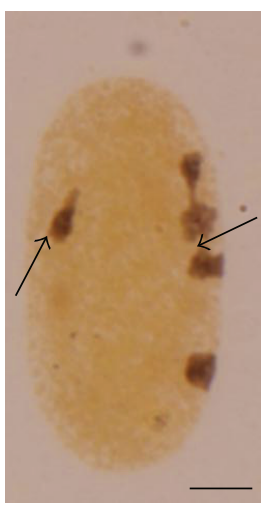

(f)

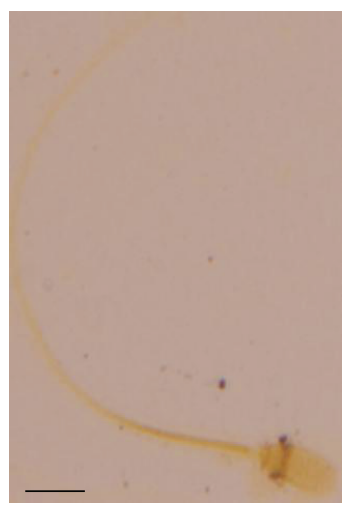

(g)

FIGURE 3: Germ cells of Oryctolagus cuniculus. Silver ion impregnation (AgNOR). (a) Interphasic spermatogonia with organized nucleolus (arrow). (b) Primary spermatocyte in zygotene stage possessing central and peripheral nucleolar corpuscles (arrows). (c) Primary spermatocyte in pachytene possessing nucleolar corpucles mainly in the peripheral chromosomal region (arrow). (d) Metaphase I. (e) Round and elongated spermatids general view. (f) Elongated spermatids possessing peripheral nucleolar corpuscles (arrows). (g) Spermatozoon with a strong silver ion impregnation in the mitochondrial sheath region. Bars (a, b, c, d, f, and g) $5 \mu \mathrm{m}$; (e) $20 \mu \mathrm{m}$.

particles, cancer, viral infections, and degenerative diseases [21]. Nucleolus size also increases and decreases in growing and resting cells, respectively, and it forms and disperses once every cell-division cycle $[48,49]$.

Nucleolar fragmentation and distribution of its fragments were evaluated by qualitative and quantitative cytochemical and cytogenetics analyses. Ultrastructural analyses were applied to verify if the nucleolar fragments produced during the meiotic division play a role in the $\mathrm{CB}$ assembling.

Qualitative cytochemical and cytogenetics analysis showed one to four central nucleolar corpuscles, could be observed in the nucleus of spermatogonia. In primary spermatocytes going through pachytene stage no organized nucleolar corpuscles were observed, and nucleolar fragments were distributed in the nuclear periphery. One to 4 organized nucleolar corpuscles could be observed in the nuclear periphery of the round spermatids after the completion of the second meiosis (Figures 1 and 3). Two major events could be noticed regarding the nucleolar cycle during meiotic cell division progression: the nucleolar fragmentation in the primary spermatocytes and the peripheral location of nucleolar corpuscles in the round spermatids.

The phenomenon of nucleolar fragmentation during prophase I and its subsequent reorganization after meiosis completion have been described in detail over the past two decades (e.g., $[17,18,51-53])$. A decrease in the amount of
C23 protein, which is responsible for rRNA transcription, and a decrease in the amount of B23 protein, which is responsible for rRNA splicing, were also observed in the nucleoli of both primary spermatocytes and round spermatids [54]. Those reports suggest that nucleolar fragmentation occurs during early meiotic prophase I and after the completion of the meiotic division smaller nucleoli are reorganized in the nuclei of round spermatids. It also has been shown that, in most chordates, there is increased nucleolar activity during prophase I, and that nucleolar activity reaches its peak during pachytene $[49,55,56]$, which helps to explain the nucleolar fragmentation occurring only after this cell-cycle stage. Organized nucleoli were not observed in the nucleus of elongated spermatids or in mature spermatozoon. The presence of a nucleolus is not necessary for the spermatozoon, because, after fecundation, the nucleoli of the male and female pronuclei in the zygote are both of maternal origin. Recent studies have suggested that the maternal nucleolus, associated with other nucleoplasmic products, is essential for embryonic development [57]. Peripheral nucleoli were also reported by [58] where the nucleolar position in the nucleus was linked to the NORs location. Species with terminal NORs possessed peripheral nucleoli while species with intercalated NORs possessed central nucleoli. The authors concluded that the distribution of nucleoli within the nuclear space of spermatocytes is nonrandom, and it is 


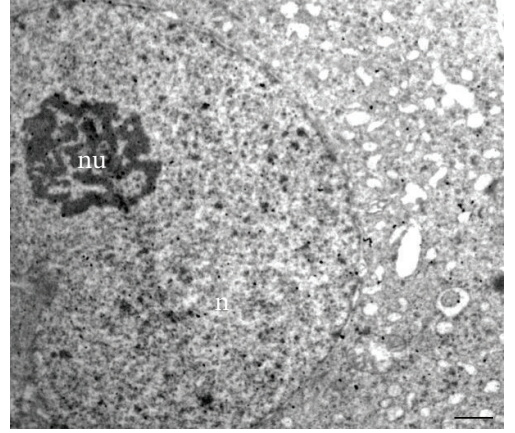

(a)

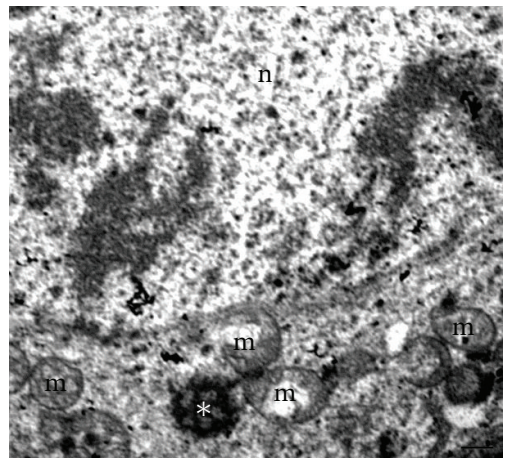

(c)

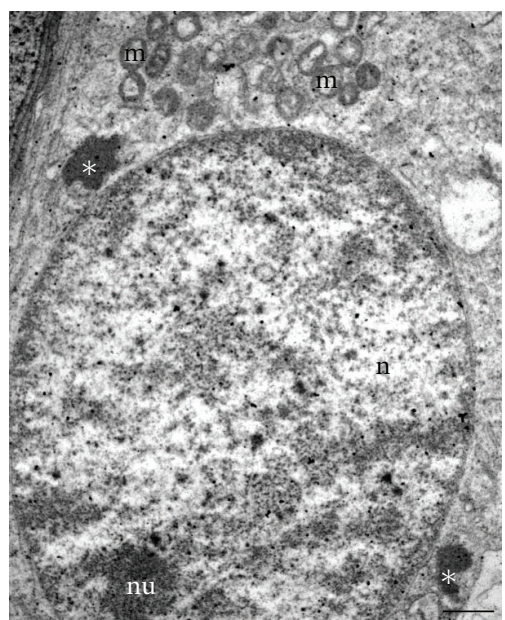

(e)

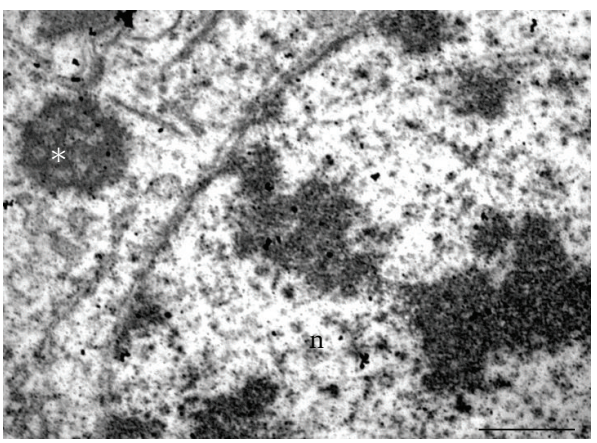

(b)

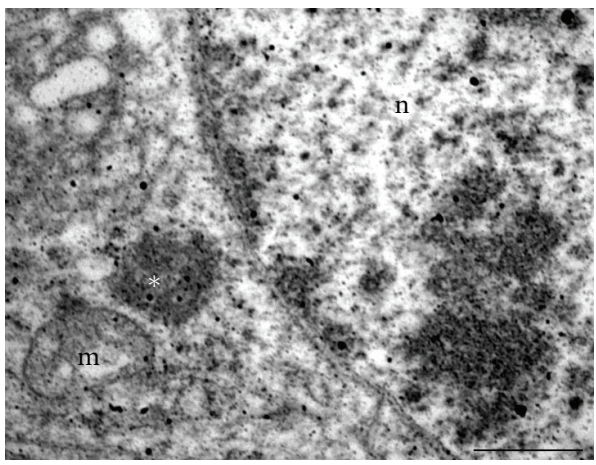

(d)

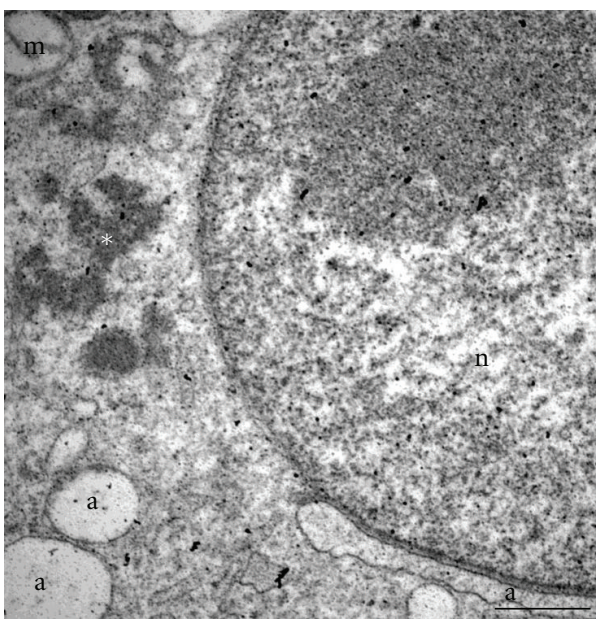

(f)

FIGURE 4: Ultrastructural analysis of Oryctolagus cuniculus germ epithelium. (a) Spermatogonia with central reticulated nucleolus (nu) organized. (b, c, and d) Primary spermatocytes in the pachytene stage with no organized nucleolus and possessing synaptonemal complex and ribonucleoprotein accumulation in the cytoplasm $(*)$. Ribonucleoprotein could join later with mitochondria $(\mathrm{m})$, or it could remain isolated. (e and f) Round spermatids with reorganized nucleolus (nu) and CB $\left(^{*}\right)$ linked to mitochondria aggregates next to the acrosomal system region (a). (n: nucleus; nu: nucleolus; m: mitochondria; ${ }^{*}$-chromatoid body; a: acrosomal system). Bars $=10 \mu \mathrm{m}$.

consistent with the existence of a species-specific meiotic nuclear architecture.

Quantitative cytochemical analyses showed that the number of nucleoli was different between the different germ cells analyzed because round spermatids had one single nucleolus more frequently than spermatogonia did (Figure 2(a)). This result suggests a decrease in the number of nucleoli during the meiotic division process. Previous studies reported that the number of nucleoli of germ cells is related to their number of RONs $[49,59]$. Diploid spermatogonia are therefore expected to have twice as many nucleoli as the round haploid spermatids, which agree with our result. There was also a notable difference in the nucleolar area of the different germ cells. We observed that nuclear and nucleolar areas of spermatogonia were larger when compared to nuclear and nucleolar areas of the round spermatids (Figure 2(b)). The size of a nucleolus is proportional to the amount of rRNA synthesized [60]; NOR size (the number 


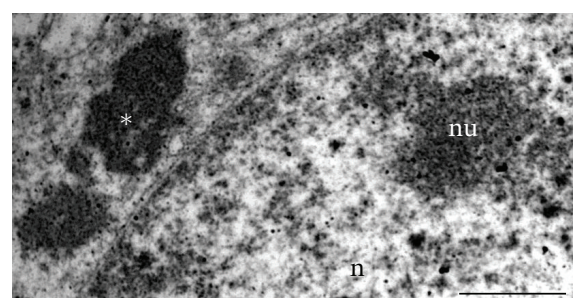

(a)

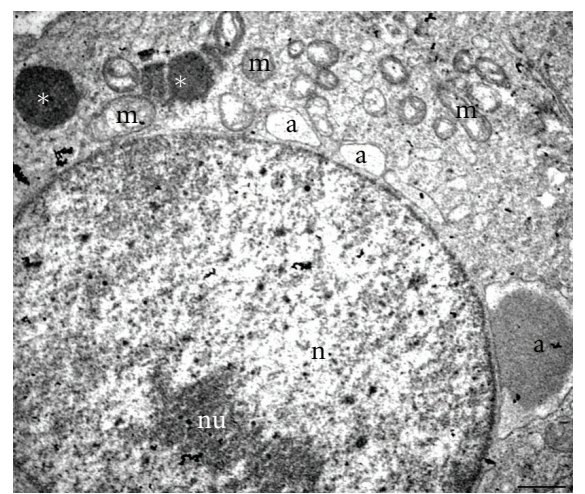

(c)

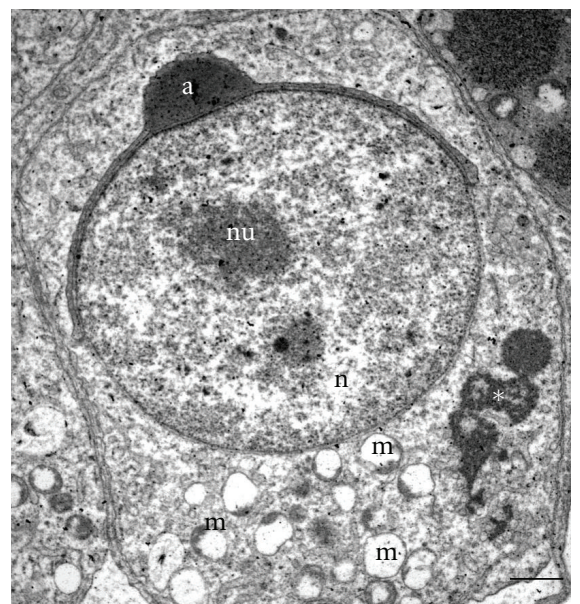

(e)

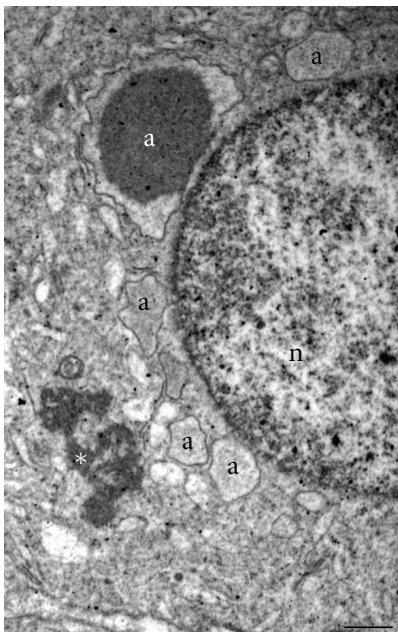

(b)

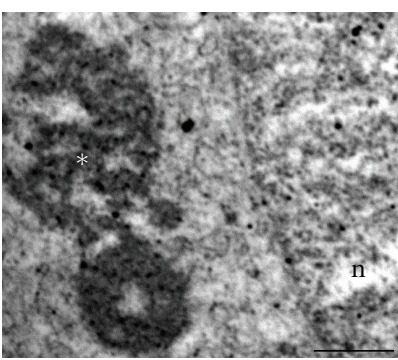

(d)

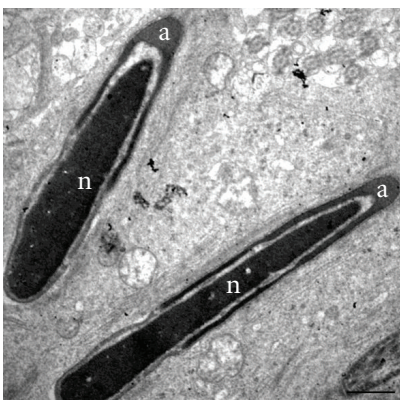

(f)

Figure 5: Ultrastructural analysis of Oryctolagus cuniculus germ epithelium. (a) Round spermatid with reorganized nucleolus (nu) and a large CB (*). (b) Round spermatids with reorganized nucleolus (nu) and CB $\left(^{*}\right)$ next to the acrosomal system (a). (c, d, and e) Elongated spermatids with reorganized nucleolus $(\mathrm{nu})$ and large $\mathrm{CB}\left({ }^{*}\right)$ linked to mitochondria aggregates $(\mathrm{m})$ moving to the nuclear posterior region (n) where the development of mitochondrial sheath and spermatozoon tail will take place. (f) Spermatozoon in maturation process with no ribonucleoprotein accumulation. (n: nucleus; nu: nucleolus; ${ }^{*}$-chromatoid body; m: mitochondria; a: acrosomal vesicle). Bars $=10 \mu \mathrm{m}$.

of rRNA cistrons) is generally correlated with its expression level [61]; hypertrophy of the nucleolus is a state in which rRNA and ribosome synthesis has increased [62]; the size of the largest nucleoli may correlate with cell-division activity and also with cellular stages having high-protein demand [63]. All of these findings may be related to the decrease in nucleolus size in the round spermatids, but its decrease can also be explained by the migration of the nucleolar fragments to the cytoplasm of germ cells in prophase I, where they may play a role in $\mathrm{CB}$ assembling as previously proposed $[14,16-18]$. If nucleolar proteins would play a role in the $C B$ physiology acting in the RNA processing or if they would be translocated to the CB because they are targeted for degradation in late steps of the spermatogenesis process is a question that still needs to be clarified. However, it has been shown that nucleolar morphology reestablishment is an important factor to the reset of lifespan in gametogenesis by eliminating age-induced cell damage [64], and some nucleolar proteins could be translocated to the $\mathrm{CB}$ during this nucleolar morphology reestablishment process. We hypothesized here the nucleolar and other nuclear components role in the molecular composition and physiology of the CB (Figure 6).

Ultrastructural analysis did not show evidences of ribonucleoprotein accumulation, which would originate the 


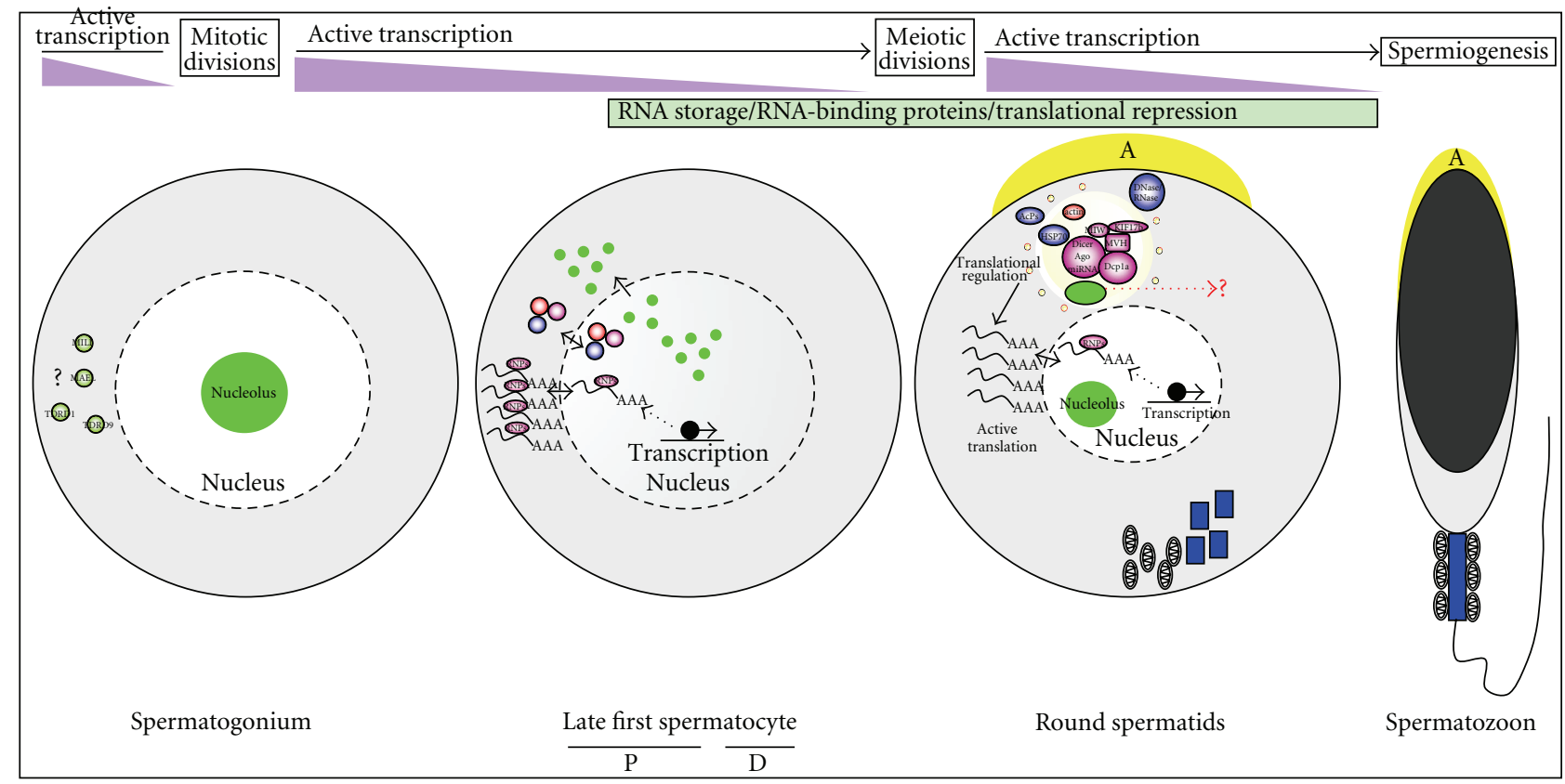

FIGURE 6: Hypothetical schematic view of the nucleolar role on the CB assembly in male germ cells. Spermatogonium is an undifferentiated male germ cell, originating in a seminal tubule and dividing by mitosis into a new generation of spermatogonia or into two first spermatocytes. In this type of cell the nucleolus is organized and active. Germ granules and granular localization of PIWI and Tudor proteins are not well characterized in spermatogonia, but MILI, MAEL, TDRD1, and TDRD9, which are molecular components of CBs, have been demonstrated in the cytoplasm of spermatogonia and/or early spermatocytes [50]. In late first spermatocytes there is a peak of nucleolar activity followed by nucleolar disorganization, and some of the nucleolar components become disperses through the cytoplasm. In this stage there is an intense transcription of mRNA that will be silent for later translation during germ-cell differentiation, and also many other nuclear products, which will play a role in the CB molecular composition, are in transit nucleus cytoplasm. There is a drastic inhibition of transcriptional activity during the meiotic divisions, and mRNA storage and translational regulation by RNA-binding proteins have an important role in the control of the synthesis of many spermatids and spermatozoa proteins [45]. In postmeiotic round spermatids, nucleolar reorganization is observed, and the transcription is active until the silencing of the haploid genome owing to compaction of the genome by the replacement of histones with protamines. In this type of cell the CB is condensed to its final shape, and it contains (a) components that play a role in the RNA processing (Miwi, KIF17b, Dicer, Ago, MVH DCP1a, miRNA-purple shapes); (b) components that act as proteasome folding and degradation sites (AcPs, HSP70, DNase/RNase-blue shapes). These components possibly play a role also in the acrosomal system formation; (c) components related to CB movement (actin-red shape). Due to the CB high mobility probably related to the presence of actin, there is a hypothesis that CB would link to mitochondria aggregates playing a role in the migration of mitochondria to the nuclear posterior region, where the formation of mitochondrial sheath and spermatozoon tail will take place. (d) The probable function of nucleolar proteins (light green shape) is still unclear. They could play some physiological role in the RNA metabolism, or even they could be targeted for degradation. After the spermiogenesis process mature male germ cell does not possess any residue of nucleolar nor even $\mathrm{CB}$ components, indicating that these materials were possibly digested at the end of the spermatogenesis process. RNPs: ribonucleoproteins; P: pachytene; D: diakinesis; A: acrosome.

$\mathrm{CB}$, in the cytoplasm of spermatogonia. Initial $\mathrm{CB}$ assembling was only observed in the cytoplasm of primary spermatocytes, after the completion of the nucleolar fragmentation (Figure 4). It has been described in the literature that the $\mathrm{CB}$ assembling often takes place after the nucleolar fragmentation $[17,18,45,52,65]$, which strongly increase the correlation between both biological process. Mature CBs were observed isolated or associated with mitochondria in the cytoplasm of primary spermatocytes (Figures 4 and 5). This association has been described in previous studies, which gave rise to the hypothesis that the $\mathrm{CB}$ may originate from intermitochondrial material [12]. Other authors have suggested that the $\mathrm{CB}$ originates from nuclear genome products and is then supplemented by mitochondrial genome products [13]. The connection between the $\mathrm{CB}$ and mitochondria may also be explained by the participation of the CB in the synthesis and transport of the apocytochrome $\mathrm{c}$, a type of cytochrome $\mathrm{c}$ isoform, which is expressed in the testis tissue [66]. The oxidase cytochrome c (COXI), an important mitochondrial component, was also reported in the CB [67]. Detection of the presence of several mitochondrial components in the $\mathrm{CB}$ and related structures may indicate the attractive possibility that germ cell nuagelike structures serve as a reconfirmation mechanism for the symbiotic interaction between mitochondria and the nuclear genome transmitted to the next generation [6]. Therefore, in this study, we suggest that the relationship between the $\mathrm{CB}$ and mitochondria can be related to the migration of these structures to the caudal nuclear region, where the development of mitochondrial sheath and spermatozoa tail 
take place. This has also been suggested by other authors $[17,18,68]$.

Round spermatids possessed reorganized nucleoli, and their $\mathrm{CBs}$ reach their maximum area. CBs also could be observed isolated or in association with mitochondria in the anterior nuclear region, next to the acrosomal system (Figures 4 and 5). The association between the $\mathrm{CB}$ and the Golgi complex had been previously described by other authors. Soderstrom and Parvinen [3], Tang et al. [69], Peruquetti et al. [17], and Peruquetti et al. [18] suggested that the interaction between these structures could be related to acrosome formation in round spermatids, because vesicles are frequently seen moving between the Golgi complex and the $\mathrm{CB}$. Large $\mathrm{CBs}$ linked to mitochondria were observed in the posterior nuclear region in elongated spermatids at the same region where the formation of the mitochondrial sheath and the spermatozoon tail will take place. As the CBs are seeing in different positions of the germ cells cytoplasm, it is considered a high-motility organelle, and this high motility is probably related to the presence of actin $[70,71]$ and calcium $[72]$ in the CB molecular composition. This high mobility was also reported by Parvinen et al. [11] in living round spermatids of rats, which had CBs in rapidly changing positions in relation to the nuclear envelope, Golgi complex, and nuclear pale chromatin areas. Ribonucleoprotein material from the $\mathrm{CB}$ was not observed in the residual bodies of elongated spermatids, indicating that this material was possibly digested at the end of the spermiogenesis process $[73,74]$.

In conclusion our data suggest that there is a decrease in the size and in the number of nucleoli during the meiotic division in the seminiferous tubules of O. cuniculus. Part of the material originated by nucleolar fragmentation could migrate to the cytoplasm and be sequestered by the CB. Both phenomena (nucleolar fragmentation and $\mathrm{CB}$ assembly) occur at the same timing during the meiotic cell cycle, and nucleolar material originated by nucleolar fragmentation could be accumulated in the $\mathrm{CB}$ for later degradation or because they would play some role in the $\mathrm{CB}$ physiology. Our results also bring more evidences that the $\mathrm{CB}$ may play important roles during the spermatogenesis process such as acrosomal system formation and mitochondrial sheath and spermatozoon tail development.

\section{Acknowledgments}

The authors would like to thank Dr. Tiago da Silveira Vasconcelos (Laboratory of Herpetology-UNESP/IB) and Dr. Thaís Billalba Carvalho (Laboratory of Fish BehaviorUNESP/IBILCE) for their help with statistical analysis. Special thanks also go to Mr. Luis Roberto Faleiros, Jr. (Laboratory of Microscopy and Microanalysis, UNESP/IBILCE) and Dr. Rosana Silistino de Souza (Laboratory of Cell Biology, UNESP/IBILCE) for their help with laboratory techniques. The authors are indebted to FAPESP (Sao Paulo Research Foundation-Grants 2005/02919-5 and 2007/04521-4) and CNPq (Brazilian Research Council, Grant 141375/2006-0) for financial support and fellowships. They would like to disclose any conflict of interests in this manuscript.

\section{References}

[1] R. A. Hess, "Spermatogenesis, overview," in Encyclopedia of Reproduction, vol. 4, Academic Press, New York, NY, USA, 1999.

[2] Y. Clermont, "Kinetics of spermatogenesis in mammals: seminiferous epithelium cycle and spermatogonial renewal," Physiological Reviews, vol. 52, no. 1, pp. 198-236, 1972.

[3] K. O. Soderstrom and M. Parvinen, "Transport of material between the nucleus, the chromatoid body and the Golgi complex in the early spermatids of the rat," Cell and Tissue Research, vol. 168, no. 3, pp. 335-342, 1976.

[4] P. T. K. Saunders, M. R. Millar, S. M. Maguire, and R. M. Sharpe, "Stage-specific expression of rat transition protein 2 mRNA and possible localization to the chromatoid body of step 7 spermatids by in situ hybridization using a nonradioactive riboprobe," Molecular Reproduction and Development, vol. 33, no. 4, pp. 385-391, 1992.

[5] E. Raz, "The function and regulation of vasa-like genes in germ-cell development," Genome Biology, vol. 1, no. 3, pp. 1-6, 2000.

[6] T. Noce, S. Okamoto-Ito, and N. Tsunekawa, "Vasa homolog genes in mammalian germ cell development," Cell Structure and Function, vol. 26, no. 3, pp. 131-136, 2001.

[7] N. Kotaja, S. N. Bhattacharyya, L. Jaskiewicz et al., "The chromatoid body of male germ cells: similarity with processing bodies and presence of Dicer and microRNA pathway components," Proceedings of the National Academy of Sciences of the United States of America, vol. 103, no. 8, pp. 2647-2652, 2006.

[8] N. Kotaja, H. Lin, M. Parvinen, and P. Sassone-Corsi, "Interplay of PIWI/Argonaute protein MIWI and kinesin KIF17b in chromatoid bodies of male germ cells," Journal of Cell Science, vol. 119, no. 13, pp. 2819-2825, 2006.

[9] Y. Costa, R. M. Speed, P. Gautier et al., "Mouse MAELSTROM: the link between meiotic silencing of unsynapsed chromatin and microRNA pathway?" Human Molecular Genetics, vol. 15, no. 15, pp. 2324-2334, 2006.

[10] M. Parvinen and L. M. Parvinen, "Active movements of the chromatoid body. A possible transport mechanism for haploid gene products," Journal of Cell Biology, vol. 80, no. 3, pp. 621$628,1979$.

[11] M. Parvinen, J. Salo, M. Toivonen, O. Nevalainen, E. Soini, and L. J. Pelliniemi, "Computer analysis of living cells: movements of the chromatoid body in early spermatids compared with its ultrastructure in snap-frozen preparations," Histochemistry and Cell Biology, vol. 108, no. 1, pp. 77-81, 1997.

[12] D. W. Fawcett, E. M. Eddy, and D. M. Phillips, "Observations on the fine structure and relationships of the chromatoid body in mammalian spermatogenesis," Biology of Reproduction, vol. 2, no. 1, pp. 129-153, 1970.

[13] A. Reunov, V. Isaeva, D. Au, and R. Wu, "Nuage constituents arising from mitochondria: is it possible?" Development Growth and Differentiation, vol. 42, no. 2, pp. 139-143, 2000.

[14] D. E. Comings and T. A. Okada, "The chromatoid body in mouse spermatogenesis: evidence that it may be formed by the extrusion of nucleolar components," Journal of Ultrasructure Research, vol. 39, no. 1-2, pp. 15-23, 1972. 
[15] K. Andersen, "Fine structure of spermatogonia and spermatocytes in the blue fox (Alopex lagopus)," Acta Veterinaria Scandinavica, vol. 19, pp. 229-242, 1978.

[16] M. Andonov, "Further study of the chromatoid body in rat spermatocytes and spermadits," Zeitschrift fur MikroskopischAnatomische Forschung-Abteilung 2, vol. 104, no. 1, pp. 4654, 1990.

[17] R. L. Peruquetti, I. M. Assis, S. R. Taboga, and M. T. V. de Azeredo-Oliveira, "Meiotic nucleolar cycle and chromatoid body formation during the rat (Rattus novergicus) and mouse (Mus musculus) spermiogenesis," Micron, vol. 39, no. 4, pp. 419-425, 2008.

[18] R. L. Peruquetti, S. R. Taboga, and M. T. V. de AzeredoOliveira, "Characterization of Mongolian gerbil chromatoid bodies and their correlation with nucleolar cycle during spermatogenesis," Reproduction in Domestic Animals, vol. 45, no. 3, pp. 399-406, 2010.

[19] D. Hernandez-Verdun, "The nucleolus today," Journal of Cell Science, vol. 99, no. 3, pp. 465-471, 1991.

[20] S. A. Gerbi, A. V. Borovjagin, and T. S. Lange, "The nucleolus: a site of ribonucleoprotein maturation," Current Opinion in Cell Biology, vol. 15, no. 3, pp. 318-325, 2003.

[21] F. M. Boisvert, S. Van Koningsbruggen, J. Navascués, and A. I. Lamond, "The multifunctional nucleolus," Nature Reviews Molecular Cell Biology, vol. 8, no. 7, pp. 574-585, 2007.

[22] V. Sirri, S. Urcuqui-Inchima, P. Roussel, and D. HernandezVerdun, "Nucleolus: the fascinating nuclear body," Histochemistry and Cell Biology, vol. 129, no. 1, pp. 13-31, 2008.

[23] T. Pederson, "Proteomics of the nucleolus: more proteins, more functions?" Trends in Biochemical Sciences, vol. 27, no. 3, pp. 111-112, 2002.

[24] W. Shou, J. H. Seol, A. Shevchenko et al., "Exit from mitosis is triggered by Tem1-dependent release of the protein phosphatase Cdc14 from nucleolar RENT complex," Cell, vol. 97, no. 2, pp. 233-244, 1999.

[25] A. F. Straight, W. Shou, G. J. Dowd et al., "Net1, a Sir2associated nucleolar protein required for rDNA silencing and nucleolar integrity," Cell, vol. 97, no. 2, pp. 245-256, 1999.

[26] R. Visintin, E. S. Hwang, and A. Amon, "Cfi 1 prevents premature exit from mitosis by anchoring Cdc14 phosphatase in the nucleolus," Nature, vol. 398, no. 6730, pp. 818-823, 1999.

[27] S. N. Garcia and L. Pillus, "Net results of nucleolar dynamics," Cell, vol. 97, no. 7, pp. 825-828, 1999.

[28] M. Carmo-Fonseca, L. Mendes-Soares, and I. Campos, "To be or not to be in the nucleolus," Nature Cell Biology, vol. 2, no. 6, pp. E107-E112, 2000.

[29] L. Montanaro, D. Treré, and M. Derenzini, "Nucleolus, ribosomes, and câncer," The American Journal of Pathology, vol. 173, pp. 301-310, 2007.

[30] P. A. San-Segundo and G. Shirleen Roeder, "Pch2 links chromatin silencing to meiotic checkpoint control," Cell, vol. 97, no. 3, pp. 313-324, 1999.

[31] M. G. Ribeiro and S. R. Lima, Iniciação às Técnicas de Preparação de Material Para Estudo e Pesquisa em Morfologia, SEGRAC Editora e Gráfica Limitada, Belo Horizonte, Brazil, 2000.

[32] M. L. S. Mello, "Cytochemistry of DNA, RNA and nuclear proteins," Brazilian Journal of Genetics, vol. 20, no. 2, pp. 257264, 1997.

[33] W. M. Howell and D. A. Black, "Controlled silver-staining of nucleolus organizer regions with a protective colloidal developer: a 1-step method," Experientia, vol. 36, no. 8, pp. 1014-1015, 1980.

[34] M. L. S. Mello and B. C. Vidal, Práticas de Biologia Celular, FUNCAMP Editora Edgard Blücher LTDA, Campinas, Brazil, 1980.

[35] R. R. Ha and J. C. Ha, Integrative Statistics for Behavioral Science, Pearson Custom Publishing, Boston, Mass, USA, 2007.

[36] J. H. Zar, Biostatiscical Analysis, Prentice Hall, New Jersey, NJ, USA, 1999.

[37] A. D. Kligerman and S. E. Bloom, "Distribuition of F-bodies, heterocromatin and nuclear organizers in the genome of the central mudminnow," Cytogenetics and Cell Genetics, vol. 18, pp. 182-196, 1977.

[38] L. A. C. Bertollo and C. A. Mestriner, "The X1X2Y sex chromosome system in the fish Hoplias malabaricus. II. Meiotic analyses," Chromosome Research, vol. 6, no. 2, pp. 141147, 1998.

[39] G. Cotta Pereira, F. Guerra Rodrigo, and J. F. David Ferreira, "The use of tannic acid glutaraldehyde in the study of elastic and elastic related fibers," Stain Technology, vol. 51, no. 1, pp. 7-11, 1976.

[40] M. L. Watson, "Staining of tissue sections for electron microscopy with heavy metals. II. Application of solutions containing lead and barium," The Journal of Biophysical and Biochemical Cytology, vol. 4, no. 6, pp. 727-730, 1958.

[41] J. H. Venable and R. A. Coggeshall, "A simplified lead citrate stain for use in electron microscopy," The Journal of Cell Biology, vol. 25, pp. 407-408, 1965.

[42] C. P. Leblond and Y. Clermont, "Spermiogenesis of rat, mouse, hamster and guinea pig as revealed by the periodic acidfuchsin sulfurous acid technique," The American Journal of Anatomy, vol. 90, no. 2, pp. 167-215, 1952.

[43] R. Korstanjea, P. C. M. O’Brienc, F. Yangc et al., "Complete homology maps of the rabbit (Oryctolagus cuniculus) and human by reciprocal chromosome painting," Cytogenetics and Cell Genetics, vol. 86, pp. 317-322, 1999.

[44] M. Parvinen, "The chromatoid body in spermatogenesis," International Journal of Andrology, vol. 28, no. 4, pp. 189-201, 2005.

[45] N. Kotaja and P. Sassone-Corsi, "The chromatoid body: a germ-cell-specific RNA-processing centre," Nature Reviews Molecular Cell Biology, vol. 8, no. 1, pp. 85-90, 2007.

[46] J. R. Head and C. K. Kresge, "Reaction of the chromatoid body with a monoclonal antibody to a rat histocompatibility antigen," Biology of Reproduction, vol. 33, no. 4, pp. 1001-1008, 1985.

[47] S. Chuma, M. Hosokawa, K. Kitamura et al., "Tdrd1/Mtr1, a tudor-related gene, is essential for male germ-cell differentiation and nuage/germinal granule formation in mice," Proceedings of the National Academy of Sciences of the United States of America, vol. 103, no. 43, pp. 15894-15899, 2006.

[48] C. S. Pikaard, "Transcription and tyranny in the nucleolus: the organization, activation, dominance and repression of ribosomal RNA genes," in The Arabidopsis Book, C. R. Somerville and E. M. Meyerowits, Eds., American Society of Plant Biologists, Rockville, Md, USA, 2002.

[49] M. Teruel, J. Cabrero, F. Perfectti, and J. P. M. Camacho, "Nucleolus size variation during meiosis and NOR activity of a B chromosome in the grasshopper Eyprepocnemis plorans," Chromosome Research, vol. 15, no. 6, pp. 755-765, 2007.

[50] O. Meikar, M. Da Ros, H. Korhonen, and N. Kotaja, "Chromatoid bodyand small RNAs in male germ cells," Reproduction, vol. 142, no. 2, pp. 195-209, 2011. 
[51] I. K. Takeuchi and Y. K. Takeuchi, "Ethanol-phosphotungstic acid and bismuth staining of spermatid nucleoli in mouse spermiogenesis," Journal of Structural Biology, vol. 103, no. 2, pp. 104-112, 1990.

[52] R. L. Peruquetti, S. R. Taboga, and M. T. V. De AzeredoOliveira, "Nucleolar cycle and its correlation with chromatoid bodies in the Tilapia rendalli (Teleostei, Cichlidae) spermatogenesis," Anatomical Record, vol. 293, no. 5, pp. 900-910, 2010.

[53] R. L. Peruquetti, S. R. Taboga, L. R. D. S. Santos, C. de Oliveira, and M. T. V. de Azeredo-Oliveira, "Nucleolar cycle and chromatoid body formation: is there a relationship between these two processes during spermatogenesis of Dendropsophus minutus (Amphibia, Anura)?" Micron, vol. 42, no. 1, pp. 8796, 2011.

[54] M. Biggiogera, S. H. Kaufmann, J. H. Shaper, N. Gas, F. Amalric, and S. Fakan, "Distribution of nucleolar proteins B23 and nucleolin during mouse spematogenesis," Chromosoma, vol. 100, no. 3, pp. 162-172, 1991.

[55] M. Schmid, C. Loser, J. Schmidtke, and W. Engel, "Evolutionary conservation of a common pattern of activity of nucleolus organizers during spermatogenesis in vertebrates," Chromosoma, vol. 86, no. 2, pp. 149-179, 1982.

[56] F. Wachtler and A. Stahl, "The nucleolus: a structural and functional interpretation," Micron, vol. 24, no. 5, pp. 473-505, 1993.

[57] B. Lefèvre, "The nucleolus of the maternal gamete is essential for life," BioEssays, vol. 30, pp. 613-616, 2008.

[58] S. Berríos, R. Fernández-Donoso, J. Pincheira, J. Page, M. Manterola, and M. Cristina Cerda, "Number and nuclear localisation of nucleoli in mammalian spermatocytes," Genetica, vol. 121, no. 3, pp. 219-228, 2004.

[59] M. Guo, D. Davis, and J. A. Birchler, "Dosage effects on gene expression in a maize ploidy series," Genetics, vol. 142, no. 4, pp. 1349-1355, 1996.

[60] T. Caspersson, Cell Growth and Cell Function, A Cytochemical Study, WW Norton, New York, NY, USA, 1950.

[61] I. Schubert and G. Kunzel, "Position-dependent NOR activity in barley," Chromosoma, vol. 99, no. 5, pp. 352-359, 1990.

[62] K. Nakamoto, A. Ito, K. Watabe et al., "Increased expression of a nucleolar Nop5/Sik family member in metastatic melanoma cells: evidence for its role in nucleolar sizing and function," American Journal of Pathology, vol. 159, no. 4, pp. 1363-1374, 2001.

[63] W. Mosgoeller, "Nucleolar ultrastructure in vertebrates," in The Nucleolus, M. O. J. Olson, Ed., Kluwer, New York, NY, USA, 2004.

[64] E. Ünal, B. Kinde, and A. Amon, "Gametogenesis eliminates age-induced cellular damage and resets life span in yeast," Science, vol. 332, pp. 1554-1557, 2011.

[65] R. Paniaguea, M. Nistal, P. Amat, and M. C. Rodriguez, "Ultrastructural observations on nucleoli and related structures during human spermatogenesis," Anatomy and Embryology, vol. 174, no. 3, pp. 301-306, 1986.

[66] R. A. Hess, L. A. Miller, J. D. Kirby, E. Margoliash, and E. Goldberg, "Immunoelectron microscopic localization of testicular and somatic cytochromes $\mathrm{c}$ in the seminiferous epithelium of the rat," Biology of Reproduction, vol. 48, no. 6, pp. 1299-1308, 1993.

[67] C. M. Haraguchi, T. Mabuchi, S. Hirata et al., "Chromatoid bodies: aggresome-like characteristics and degradation sites for organelles of spermiogenic cells," Journal of Histochemistry and Cytochemistry, vol. 53, no. 4, pp. 455-465, 2005.
[68] J. T. Soley, "Centriole development and formation of the flagellum during spermiogenesis in the ostrich (Struthio camelus)," Journal of Anatomy, vol. 185, no. 2, pp. 301-313, 1994.

[69] X. M. Tang, M. F. Lalli, and Y. Clermont, "A cytochemical study of the Golgi apparatus of the spermatid during spermiogenesis in the rat," American Journal of Anatomy, vol. 163, no. 4, pp. 283-294, 1982.

[70] H. Walt and B. L. Armbruster, "Actin and RNA are components of the chromatoid bodies in spermatids of the rat," Cell and Tissue Research, vol. 236, no. 2, pp. 487-490, 1984.

[71] G. Aumuller and J. Seitz, "Immunocytolchemical localization of actin and tubulin in rat testis and spermatozoa," Histochemistry, vol. 89, no. 3, pp. 261-267, 1988.

[72] M. D. Andonov and G. N. Chaldakov, "Morphological evidence for calcium storage in the chromatoid body of rat spermatids," Experientia, vol. 45, no. 4, pp. 377-378, 1989.

[73] B. Sud, "Morphological and histochemical studies of the chromatoid body and related elements in the spermatogenesis of rat," Quarterly Journal of Microscopical Science, vol. 102, pp. 273-292, 1961.

[74] S. Yokota, "Historical survey on chromatoid body research," Acta Histochemica et Cytochemica, vol. 41, no. 4, pp. 65-82, 2008. 

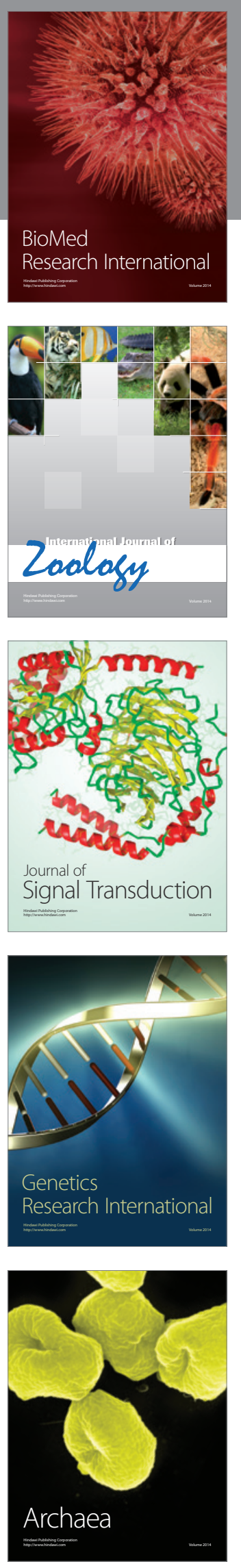
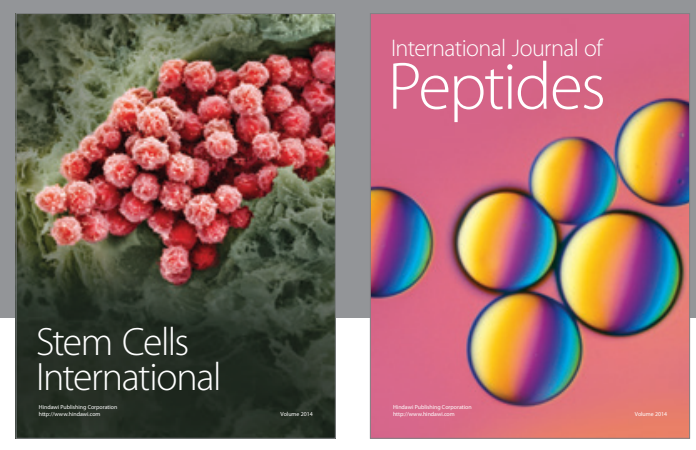

Submit your manuscripts at

http://www.hindawi.com
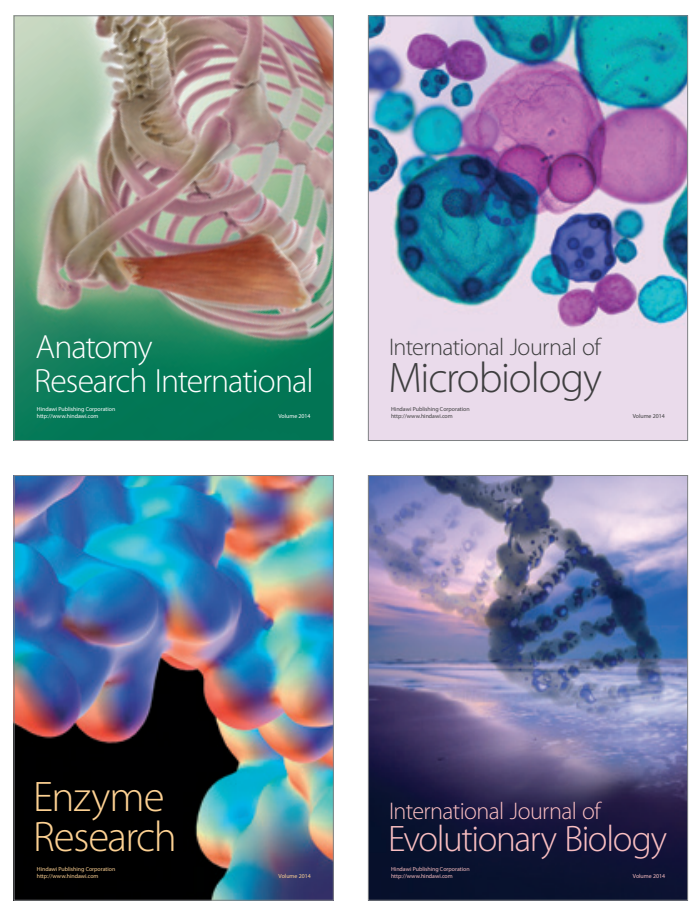
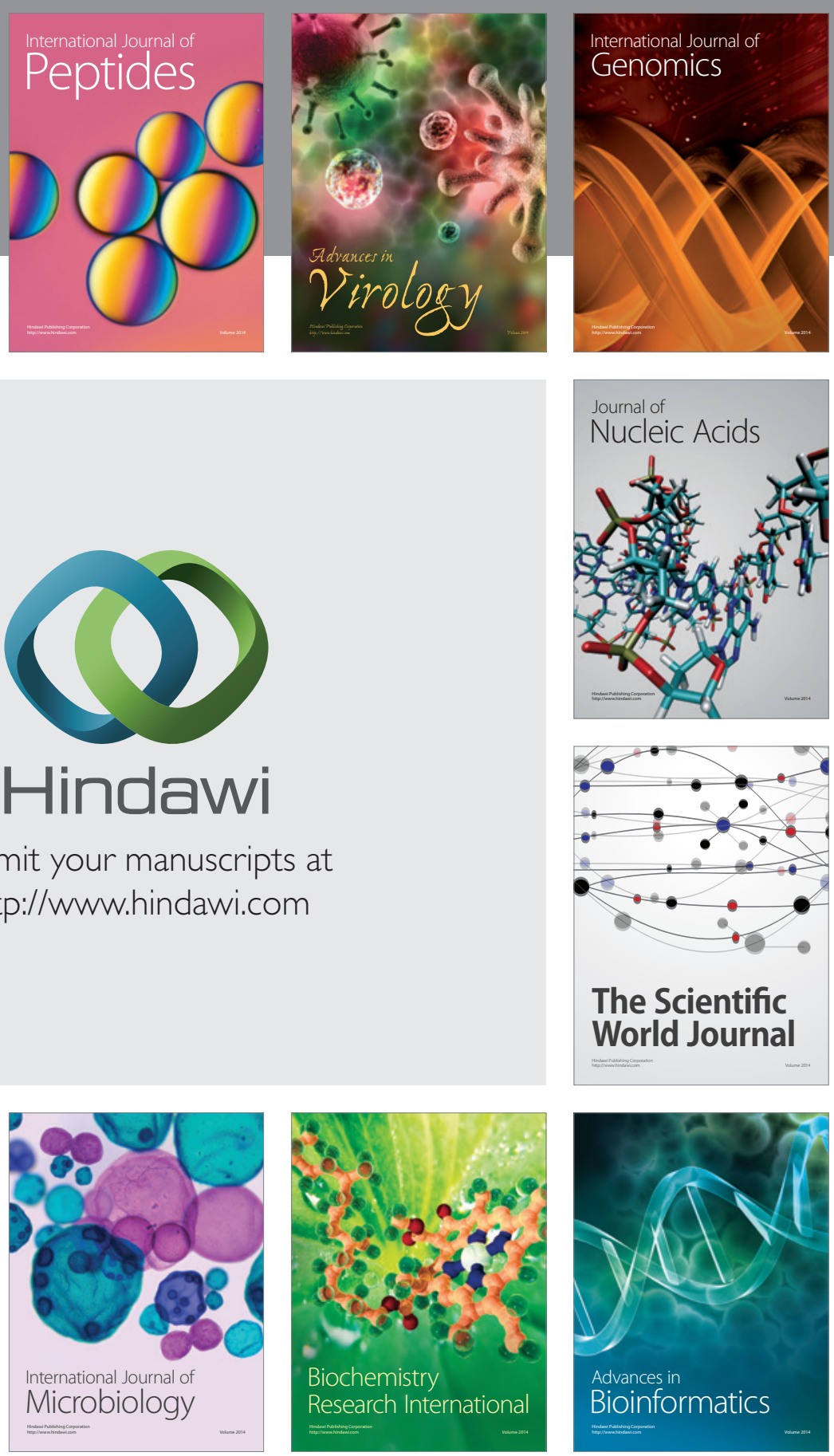

The Scientific World Journal
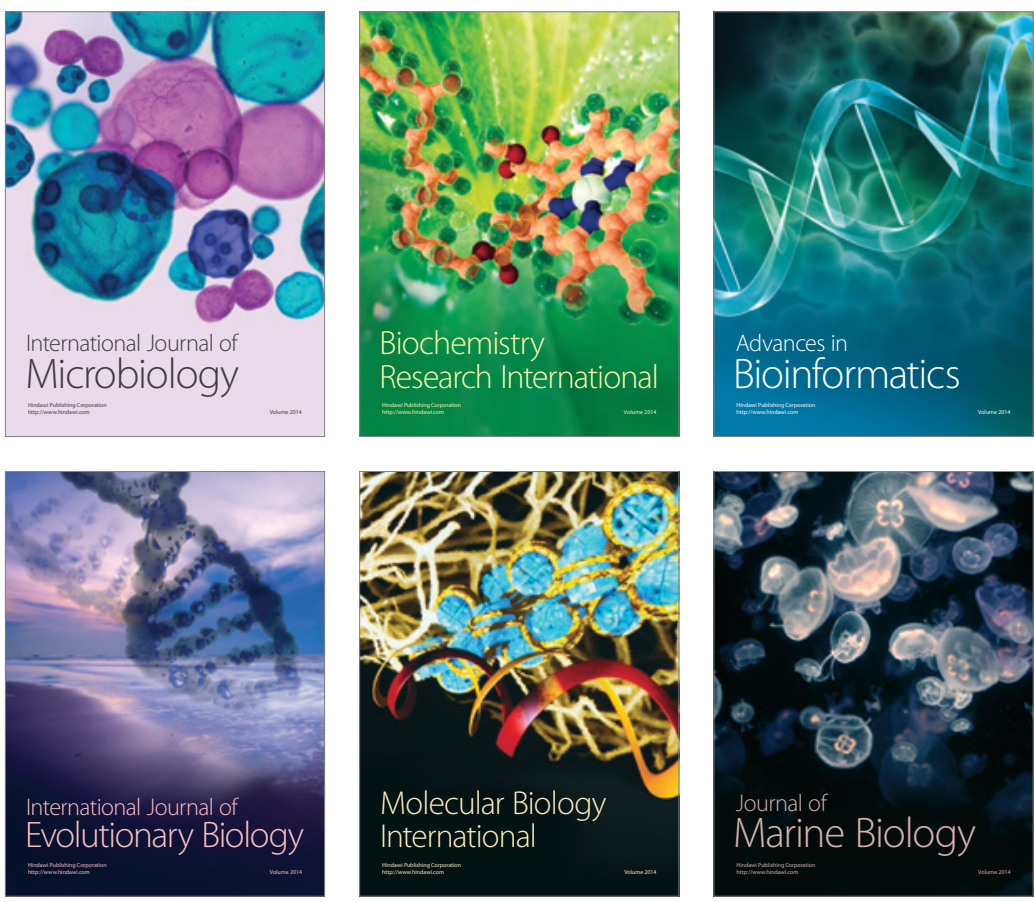